Article

\title{
Investigating the Potential of Transmucosal Delivery of Febuxostat from Oral Lyophilized Tablets Loaded with a Self-Nanoemulsifying Delivery System
}

\author{
Yasir A. Al-Amodi ${ }^{1}$, Khaled M Hosny ${ }^{1,2}$, Waleed S. Alharbi ${ }^{1} \oplus$, Martin K. Safo ${ }^{3}$ and \\ Khalid M El-Say $1,4, *$ (D) \\ 1 Department of Pharmaceutics, Faculty of Pharmacy, King Abdulaziz University, Jeddah 21589, Saudi Arabia; \\ yaser.vip99@gmail.com or yalamodi0003@stu.kau.edu.sa (Y.A.A.-A.); Kmhomar@kau.edu.sa (K.M.H.); \\ wsmalharbi@kau.edu.sa (W.S.A.) \\ 2 Department of Pharmaceutics and Industrial Pharmacy, Faculty of Pharmacy, Beni-Suef University, \\ Beni-Suef 62511, Egypt \\ 3 Department of Medicinal Chemistry, and the Institute for Structural Biology, Drug Discovery and \\ Development, School of Pharmacy, Virginia Commonwealth University, Richmond, VA 23298, USA; \\ msafo@vcu.edu \\ 4 Department of Pharmaceutics and Industrial Pharmacy, Faculty of Pharmacy, Al-Azhar University, \\ Cairo 11651, Egypt \\ * Correspondence: kelsay1@kau.edu.sa; Tel.: +96-658-293-4511
}

Received: 30 April 2020; Accepted: 8 June 2020; Published: 10 June 2020 updates

\begin{abstract}
Gout is the most familiar inflammatory arthritis condition caused by the elevation of uric acid in the bloodstream. Febuxostat (FBX) is the latest drug approved by the United States Food and Drug Administration (US FDA) for the treatment of gout and hyperuricemia. FBX is characterized by low solubility resulting in poor gastrointestinal bioavailability. This study aimed at improving the oral bioavailability of FBX by its incorporation into self-nanoemulsifying delivery systems (SNEDS) with minimum globule size and maximum stability index. The SNEDS-incorporated FBX was loaded into a carrier substrate with a large surface area and lyophilized with other excipients to produce a fluffy, porous-like structure tablet for the transmucosal delivery of FBX. The solubility of FBX was studied in various oils, surfactants, and cosurfactants. Extreme vertices design was utilized to optimize FBX-SNEDS, and subsequently loaded into lyophilized tablets along with suitable excipients. The percentages of the main tablet excipients were optimized using a Box-Behnken design to develop self-nanoemulsifying lyophilized tablets (SNELTs) with minimum disintegration time and maximum drug release. The pharmacokinetics parameters of the optimized FBX-SNELTs were tested in healthy human volunteers in comparison with the marketed FBX tablets. The results revealed that the optimized FBX-SNELTs increased the maximum plasma concentration $\left(\mathrm{C}_{\max }\right)$ and decreased the time to reach $C_{\max }\left(T_{\max }\right)$ with a large area under the curve (AUC) as a result of the enhanced relative oral bioavailability of $146.4 \%$. The significant enhancement of FBX bioavailability is expected to lead to reduced side effects and frequency of administration during the treatment of gout.
\end{abstract}

Keywords: bioavailability; febuxostat; gout; lyophilized tablets; self-nanoemulsifying delivery system

\section{Introduction}

Hyperuricemia is a metabolic disorder that is characterized by an increase in serum urate over a threshold value that leads to the growth of crystals of monosodium urate in tissues and around the joints, and when it becomes symptomatic in a patient, it is diagnosed as gout [1]. Gout is the most familiar inflammatory arthritis condition in men above 40 years, although it is increasingly occurring 
in postmenopausal women [2]. In addition, the prevalence of gout has kept pace with increasing population growth. For example, in China 15.3 million were diagnosed with chronic gout in 2013, and the number is expected to increase to 17.7 million in 2021 [3].

Febuxostat (FBX) is the latest drug developed for hyperuricemia and gout treatment [4]. The United States Food and Drug Administration (US FDA) and European Medicines Agency (EMA) approved FBX for patients who have an inadequate reduction in serum uric acid level or who do not tolerate allopurinol [5]. At $80 \mathrm{mg}$ and $120 \mathrm{mg}$ doses, FBX was more potent at decreasing serum uric acid level than allopurinol at doses of $200 \mathrm{mg}$ and $300 \mathrm{mg}$ as demonstrated by clinical comparative studies [6]. Of note is that FBX, which is practically insoluble in water [7], offers dissolution rate limited-absorption, consequently leading to poor and variable oral bioavailability [8].

Owing to its massive applicative potential, nanotechnology is considered one of the foremost technologies of the 21st century. In the pharmaceutical field, nanotechnology has led to improvement in the efficacy both of novel and old drugs, with the potential to offer state-of-the-art solutions for all therapeutic agents, and diagnostic tools for varied diseases $[9,10]$.

Self-nanoemulsifying delivery systems (SNEDS) and the nanometric-sized transparent systems produced on dilution, known as nanoemulsions (NEs), have been widely studied for their abundant potential applications [11-16]. SNEDS offered greater stability when compared to other lipid-based drug delivery systems $[17,18]$. Also, SNEDS improved the solubility and subsequently the oral bioavailability of lipophilic drugs [19].

Due to potential incompatibility and liquid leakage from capsules filled with liquid SNEDS, as well as expensive capsule liquid-filling technology, solid SNEDS are desired [20]. Solid SNEDS can be loaded onto a solid carrier to provide solid dosage forms to augment drug stability, dose accuracy, and patient convenience [21-23]. Porous carriers, such as silicon dioxide, magnesium aluminometasilicate, dibasic calcium phosphate, and calcium silicate have been used in the solidification of SNEDS for their great potential in adsorbing liquid [24-28]. The lyophilization technique brings numerous advantages of freeze-dried dosage forms such as quick disintegration, excellent stability, and respectable preservation. In this process, water is sublimated directly from the solid ice state into the vapor gas state. This will permit less damage to the substance than any other drying technique that depends on a higher temperature. Furthermore, flavors, odors, and other excipients are generally unaffected. Also, the lyophilization process creates a porous-like structure that promotes the rapid rehydration and solubilization of the tablet. The produced lyophilized tablet, when placed in the mouth, can be rapidly dispersed or dissolved in saliva without the need for water or chewing and can be swallowed in the form of a liquid, increasing its dissolution and absorption, and consequently its bioavailability [23,29]. Therefore, the development of self-nanoemulsifying lyophilized tablets (SNELTs) is highly preferred owing to their scalability and robustness, and their ability to gain all the advantages of a liquid system. A variety of sugars have been used as cryoprotectants during the dehydration of the tablets [30].

The aim of this study was to improve the poor bioavailability of FBX by multiconcerted mechanisms, primarily by utilizing nanotechnology through the preparation of FBX in the form of SNEDS, utilizing mixture design to minimize the globule size into a nanosized range to improve FBX solubility. The FBX-SNEDS were loaded into fumed silica to provide a large surface area and improve their dispersion into an aqueous gelatin solution. Then, the other excipients such as Croscarmellose sodium, lactose, and xylitol were subsequently added. All the components were homogeneously mixed until the formation of a slurry that was poured into empty pockets of tablet blister packs that were finally lyophilized. The incorporation of the resultant mixture in a lyophilized tablet produced a tablet with a fluffy, porous-like structure, which was then optimized using the Box-Behnken design (BBD). The optimized tablet was subjected to an in vivo pharmacokinetic study on human volunteers in comparison with the marketed tablets. The resulting oral transmucosal FBX-SNELTs afford a porous tablet with fast dissolution and high bioavailability and are expected to lead to better patient compliance. 


\section{Materials and Methods}

\subsection{Materials}

Febuxostat (FBX) powder was a kind gift from SPIMACO Addwaeih's. (Riyadh, Saudi Arabia). Propylene glycol and clove oil were purchased from TEDIA Company, Inc. (Fairfield, OH, USA). Olive oil, linoleic acid 60\% and isopropyl myristate 96\% were purchased from Acros Organics (Morris Plains, NJ, USA). Microcrystalline cellulose (Avicel ${ }^{\circledR}$ PH-101), fumed silica $(0.007 \mu \mathrm{m})$, gelatin, Tween 80, Tween 20, polyethylene glycol (PEG) 200 and 400, triacetin, oleic acid, Lauroyl polyoxylglycerides (Gelucire ${ }^{\circledR} 44 / 14$, hydrogenated coconut oil with PEG 32), mannitol, castor oil, methanol, polyethylene glycol 40 stearate (Myrj ${ }^{\circledR}$ 52), glycerin, hydroxypropyl methylcellulose (HPMC), xylitol, croscarmellose sodium (Ac-Di-Sol $\left.{ }^{\circledR}\right)$, and starch were purchased from Sigma-Aldrich (St. Louis, MO, USA). Propylene glycol dicarprylate, Labrafil ${ }^{\circledR}$ M1944, Labrafac ${ }^{\circledR}$ WL1349, Labrasol ${ }^{\circledR}$, Transcutol ${ }^{\circledR}$, and Kolliphor ${ }^{\circledR}$ were purchased from Gattefosse (Saint-Priest, France). Lactose was obtained from the Spectrum chemical manufacturing corporation (Gardena, CA, USA). All other chemicals and solvents were of analytical grades.

\subsection{Solubility Studies of FBX in Different Self-Nanoemulsion Components}

FBX solubility in oils, namely Labrafac ${ }^{\circledR}$ WL1349, castor oil, olive oil, clove oil, oleic acid, isopropyl myristate 96\%, Lauroyl polyoxylglycerides, triacetin, and linoleic acid 60\%, was determined. Also, FBX solubility was determined in surfactants such as Tween 80, Tween 20, polyethylene glycol 40 stearate, propylene glycol dicarprylate, Labrafil ${ }^{\circledR}$ M1944, glyceryl distearate, Labrasol ${ }^{\circledR}$, and Kolliphor ${ }^{\circledR}$. Solubility in cosurfactants like PEG 200, PEG 400, propylene glycol, Transcutol ${ }^{\circledR}$, and glycerin was also determined. The experiment was performed by dissolving an excess amount of FBX in $3 \mathrm{~mL}$ of each liquid separately. The mixture was shaken in a thermostatically controlled shaking water bath (Model 1031; GFL Corporation, Burgwedel, Germany) at $25 \pm 0.5^{\circ} \mathrm{C}$ for $48 \mathrm{~h}$ till equilibrium. $1 \mathrm{ml}$ of this mixture was centrifuged at $3000 \mathrm{rpm}$ for $20 \mathrm{~min}$ and the concentration of FBX was determined spectrophotometrically at $316 \mathrm{~nm}$ using a UV-VIS spectrophotometer (Jenway 7315; Bibby Scientific Limited, Stone, UK).

\subsection{Construction of Pseudo-Ternary Phase Diagram}

Based on the solubility studies, a ternary phase diagram was established using the chosen oil (castor oil), surfactant (polyethylene glycol-40-stearate), and cosurfactant (Transcutol ${ }^{\circledR}$ ) to identify the levels of self-nanoemulsion component, which spontaneously form a clear NE after dilution with water.

\subsection{Formulation of FBX-Loaded SNEDS according to the Mixture Design}

The extreme vertices design of the special cubic model was utilized to statistically optimize the effects of SNEDS components in a randomized order [31]. The three-component system was planned to use the percent of oil phase (castor oil $\left(X_{1}\right)$ ), the percent of surfactant (polyethylene glycol 40 stearate $\left(X_{2}\right)$ ), and the percent of cosurfactant (Transcutol ${ }^{\circledR}\left(X_{3}\right)$ ) to develop a SNEDS with minimum globule size and maximum stability index. The dependent variables were the mean globule size $\left(\mathrm{Y}_{1}\right)$ and the stability index $\left(\mathrm{Y}_{2}\right)$. The components and their ratios selected to perform the mixture design are summarized in Table 1. For any mixture, the total of the three components always added to $100 \%$. The correlations between the components and the obtained responses were statistically analyzed using the statistical package Statgraphics ${ }^{\circledR}$ Centurion 18 Software (StatPoint, Inc., Warrenton, VA, USA). 
Table 1. Components of the mixture design and their selected levels.

\begin{tabular}{ccc}
\hline \multirow{2}{*}{ Component } & \multicolumn{2}{c}{ Level } \\
\cline { 2 - 3 } & Low & High \\
\hline Oil percentage $\left(\mathrm{X}_{1}\right)$ & 10 & 15 \\
Surfactant percentage $\left(\mathrm{X}_{2}\right)$ & 40 & 60 \\
Co-surfactant percentage $\left(\mathrm{X}_{3}\right)$ & 30 & 50 \\
\hline
\end{tabular}

\subsection{Evaluation of the FBX-NE Formulations}

\subsubsection{Visual Inspection for Emulsification Ability}

The FBX-SNEDS was inspected visually for its clarity and its ability to be emulsified spontaneously upon mixing of its components. Briefly, a specific weight $(50 \mathrm{mg})$ of the SNEDS formulation was placed into $100 \mathrm{~mL}$ of distilled water and observed visually for the emulsification ability. The appearance of the NE after gentle agitation was graded as very cloudy, cloudy, or clear. Visual observations were made immediately after dilution for spontaneous emulsification, transparency, phase separation, and drug precipitation [16].

\subsubsection{Globule Size Determination}

Aliquots of $20 \mathrm{~mL}$ distilled water containing $100 \mathrm{mg}$ of each formulation were used to determine the globule size by dynamic light scattering using a Zetatrac particle size analyzer from Microtrac Inc. (Montgomeryville, PA, USA).

\subsubsection{Thermodynamic Stability Studies}

The NE formulations were examined for their thermodynamic stability [32]. The formulations were exposed to three freeze-thaw cycles, with each cycle comprising $12 \mathrm{~h}$ freezing at $-20^{\circ} \mathrm{C}$, followed by $12 \mathrm{~h}$ thawing at $+25^{\circ} \mathrm{C}$. The resultant formulations were examined for a change in globule size to ensure the stability of the NE. The stability index for the NE was calculated from Equation (1).

$$
\text { Stability index }=[(\text { Initial size }- \text { Change in size }) / \text { Initial size }] \times 100
$$

\subsubsection{Morphology of NE}

A transmission electron microscope (TEM, H7500, Hitachi, Japan) was used to analyze the morphology and structure of the optimized formulation. The formulation was further used to prepare the FBX-SNELTs.

\subsection{Preparation of FBX-SNELTS}

FBX-SNELTs were prepared according to a previously reported method [23]. Briefly, the specified weight of FBX-SNEDS was mixed with $200 \mathrm{mg}$ fumed silica, $100 \mathrm{mg}$ xylitol, $100 \mathrm{mg}$ mannitol, and $200 \mathrm{mg}$ lactose. Croscarmellose sodium percentage, gelatin solution concentration, and hydroxypropyl methylcellulose percentage were added in varying percentages to study their effect on the in vitro disintegration and in vitro dissolution of the prepared FBX-SNELTs.

\subsection{Optimization of FBX-SNELTS}

The results of the fifteen formulations were evaluated using analysis of variance (ANOVA) followed by multiple response optimization with the Statgraphics software. The optimum concentrations for the three variables were established to develop FBX-SNELTs with minimum disintegration time and an optimum drug release profile. The optimized FBX-SNELT was prepared and evaluated for weight uniformity, thickness, content uniformity, in vitro disintegration, and in vitro dissolution. 


\subsection{In Vivo Pharmacokinetic Studies}

An open-label, one-period, parallel design comprising two weeks of screening preceding $24 \mathrm{~h}$ study periods was conducted. The chosen volunteers ( 6 male and 6 female with ages ranging between 22 and 39) were given a single dose of either optimized FBX-SNELT equivalent to $20 \mathrm{mg}$ (test), or marketed FBX tablet equivalent to $20 \mathrm{mg}$ (reference). The study was approved by the Ethics Committee of the General Hospital of Beni-Suef University, Egypt with approval number FMBSU-106-19 in March 2019. Also, the study was conducted according to the Helsinki agreement protocol. An hour before dosing, a cannula was inserted into the volunteer's forearm and kept there for $24 \mathrm{~h}$. After the administration of the formulation, blood samples were collected at a predetermined time interval of $24 \mathrm{~h}$. The plasma was separated and the concentration of FBX in each sample was determined using a Shimadzu Prominence HPLC system (Shimadzu Corp., Kyoto, Japan) with the fluorescence detection method at excitation and emission wavelengths of 320 and $380 \mathrm{~nm}$, respectively [33]. In brief, after the addition of an internal standard (2-naphthoic acid), the proteins were removed from plasma samples $(0.25 \mathrm{~mL})$ by the addition of $0.25 \mathrm{~mL}$ of acetonitrile, mixed, and centrifuged, and the resulting supernatant was acidified with $25 \mu \mathrm{L}$ of glacial acetic acid. FBX and the internal standard were resolved from the matrix components using a Nucleodur MN-C18 column, $5 \mu \mathrm{m}, 250 \times 4.6 \mathrm{~mm}$ (Macherey-Nagel, Düren, Germany). The mobile phase comprised $0.03 \%$ glacial acetic acid in water and acetonitrile (55:45, v/v). FBX showed a linear calibration curve ranging from 0.005 to $25 \mu \mathrm{g} \mathrm{mL}{ }^{-1}$ with a correlation coefficient of $>0.997$ and with a minimum limit of quantification with a $250 \mu \mathrm{L}$ plasma sample of $0.005 \mu \mathrm{g} \mathrm{mL}{ }^{-1}$. The pharmacokinetic parameters were determined by a non-compartmental pharmacokinetic model utilizing PK Solver 2.0 software (an add-in program for pharmacokinetic data). The results were expressed as mean \pm SD and analyzed using GraphPad Prism 8 software (San Diego, CA, USA).

\section{Results and Discussion}

\subsection{Solubility Studies}

Figure 1 showed the solubility of FBX in the various oils, surfactants, and cosurfactants. The highest solubility of FBX in the oils was observed with castor oil $(228.37 \mathrm{mg} / \mathrm{mL})$ (Figure 1a); in the surfactants, with polyethylene glycol-40-stearate $(435.2 \mathrm{mg} / \mathrm{mL}$ ) (Figure $1 \mathrm{~b}$ ); and in the cosurfactants, with Transcutol $^{\circledR}(593.3 \mathrm{mg} / \mathrm{mL})$ (Figure 1c). The surfactants Labrasol, Tween 20, Tween 80 and Kolliphor, as well as the cosurfactant PEG 400, also resulted in significant solubility of FBX (Figure 1).

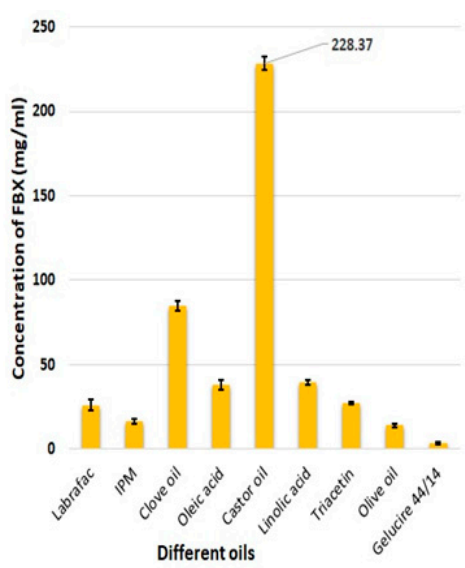

a)

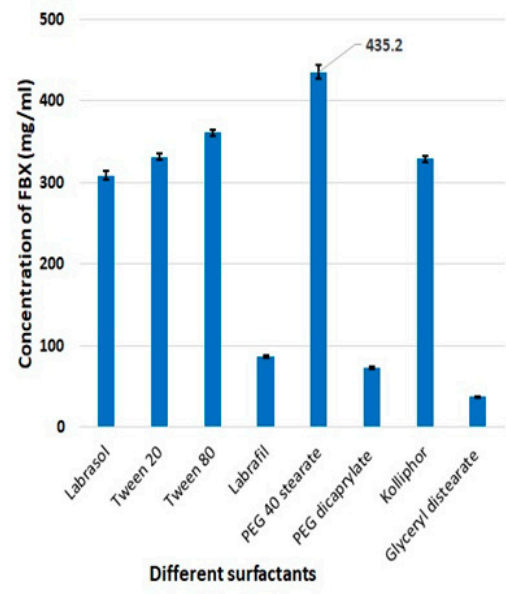

b)

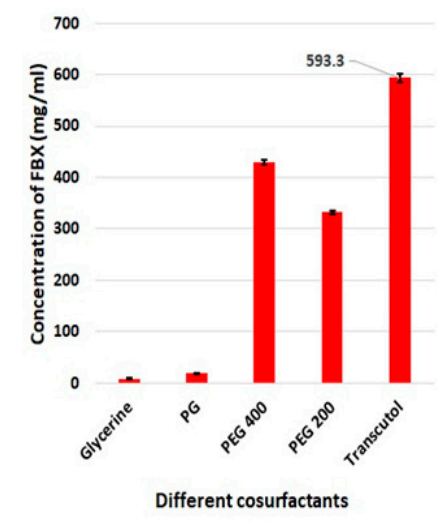

c)

Figure 1. Solubility of FBX in different (a) oils, (b) surfactants, and (c) cosurfactants.

The ability of a nanoemulsion (NE) to maintain a drug in solubilized form is markedly affected by the solubility of the drug in the oil phase [34]. Castor oil has been massively used in the pharmaceutical 
field as a solvent for poorly soluble drugs prepared in the form of an emulsion. It has been suggested that the presence of a hydroxyl functional group in ricinoleic acid, the main constituent of castor oil, aids the stability of the formed emulsion [35]. For surfactants, the nonionic polyethylene glycol 40 stearate is is commonly used in the formulation of NEs for oral or parenteral use due to its limited toxicity and high biocompatibility. Polyethylene glycol 40 stearate also has a suitable hydrophilic-lipophilic balance (HLB) value of 17 [36]. Surfactants with an HLB value greater than 10 are usually utilized in the formulation of emulsions intended to form a fine oil in water $(\mathrm{o} / \mathrm{w}) \mathrm{NE}$ when dispersed in gastrointestinal fluids [37]. Cosurfactants, e.g., Transcutol ${ }^{\circledR}$, are usually used to obtain stable NE systems as they further decrease the interfacial tension between the oily and aqueous phases of the emulsion, and enhance the fluidity of the interface [34]. In the present study, castor oil, polyethylene glycol 40 stearate, and Transcutol ${ }^{\circledR}$, which incidentally resulted in a high solubility of FBX, were selected as the components of choice for the formulation of FBX-SNEDS.

\subsection{Construction of Pseudo-Ternary Phase Diagram}

A pseudo-ternary phase diagram was established to identify the levels of SNEDS components which spontaneously form clear NEs after dilution with water as a preliminary test for the mixture design. Figure $2 \mathrm{a}$ shows the levels of the components that lie in the area in which the formed mixture spontaneously gives a NE after dilution. These levels were $10 \%$ to $15 \%$ ( $w / w)$ for oil, $40 \%$ to $60 \%(w / w)$ for surfactant, and $30 \%$ to $50 \%(w / w)$ for cosurfactant.

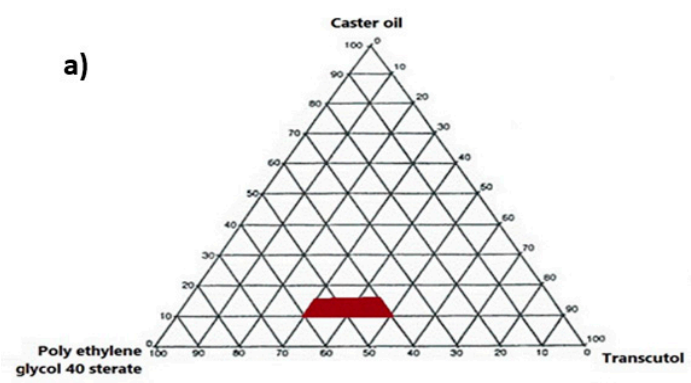

c)

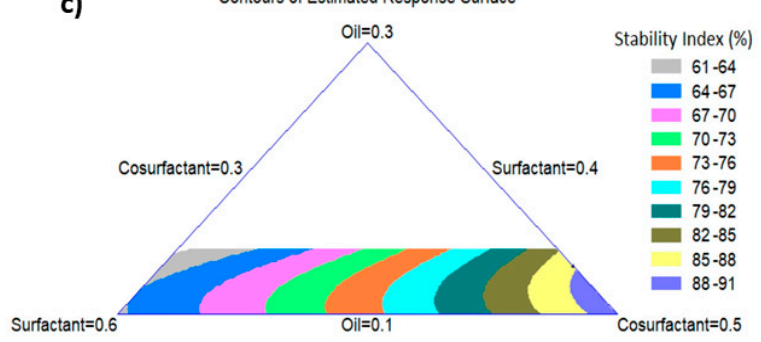

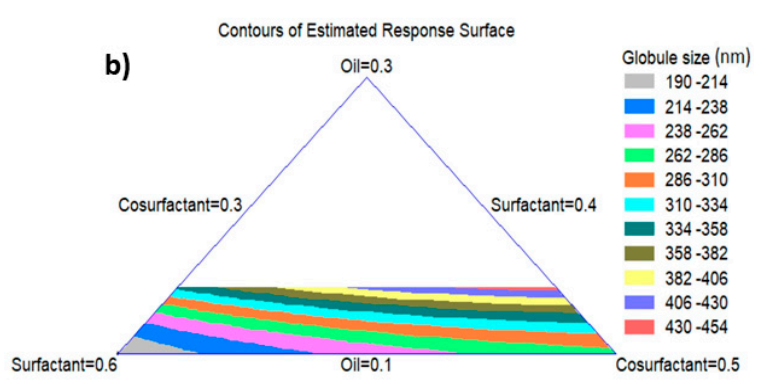

d)

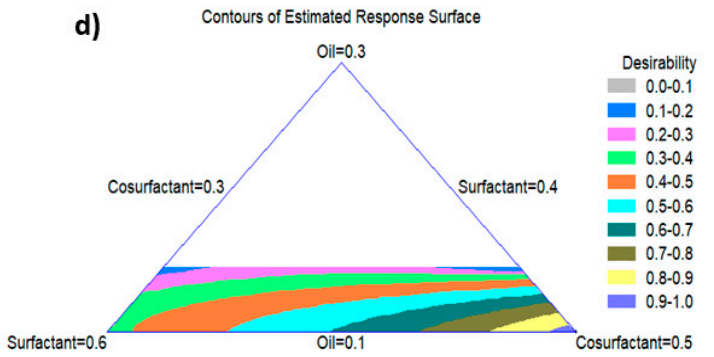

Figure 2. Pseudo-ternary phase diagrams of the selected nanoemulsion system (a), Two-dimensional (2D) contour plots of the estimated response surface for the effect of variables on FBX-SNEDS (b-d). The red area in figure (a) represents the clear nanoemulsion region that was selected as a border of the mixture experimental design space.

\subsection{Optimization of FBX-NE Formulations}

\subsubsection{Effect of NE Components on the Globule Size}

The composition of the SNEDS formulations and the mean of the observed $\mathrm{Y}_{1}$ and $\mathrm{Y}_{2}$ are listed in Table 2. The results of the globule size varied from $175.7 \mathrm{~nm}$ to $452.8 \mathrm{~nm}$ and these results fitted to the special cubic model with a $p$-value of 0.0004 . This variability in the globule size of the formulations resulted from the difference in the proportion of NE components. The contour plot displays the effect 
of the mixture components on the globule size of the NE as demonstrated in Figure $2 \mathrm{~b}$. The regression equation of the fitted special cubic model for the globule size $\left(\mathrm{Y}_{1}\right)$ was generated using Equation (2).

Globule size $\left(Y_{1}\right)=2043.42 X_{1}+193.121 X_{2}+278.409 X_{3}-1627.05 X_{1} X_{2}-1418.95 X_{1} X_{3}$ $+43.1492 \mathrm{X}_{2} \mathrm{X}_{3}+468.679 \mathrm{X}_{1} \mathrm{X}_{2} \mathrm{X}_{3}$.

Table 2. Composition matrix and the observed mean globule size and stability index of FBX-NE formulations as suggested by the mixture design.

\begin{tabular}{cccccc}
\hline \multirow{2}{*}{ Formula Code } & \multicolumn{3}{c}{ Mixture Components } & \multicolumn{2}{c}{ Dependent Responses } \\
\cline { 2 - 6 } & $\mathbf{X}_{\mathbf{1}} \mathbf{( \% )}$ & $\mathbf{X}_{\mathbf{2}} \mathbf{( \% )}$ & $\mathbf{X}_{\mathbf{3}} \mathbf{( \% )}$ & $\mathbf{Y}_{\mathbf{1}} \mathbf{( n m )}$ & $\mathbf{Y}_{\mathbf{2}} \mathbf{( \% )}$ \\
\hline NE-1 & 10 & 60 & 30 & 202.2 & 61 \\
NE-2 & $\mathbf{1 0}$ & $\mathbf{4 0}$ & $\mathbf{5 0}$ & $\mathbf{1 7 5 . 7}$ & $\mathbf{9 1}$ \\
NE-3 & 15 & 55 & 30 & 355.7 & 59 \\
NE-4 & 15 & 40 & 45 & 452.8 & 85 \\
NE-5 & 11.25 & 54.375 & 34.375 & 210.7 & 72 \\
NE-6 & 11.25 & 44.375 & 44.375 & 288.7 & 80 \\
NE-7 & 13.75 & 51.875 & 34.375 & 366.9 & 70 \\
NE-8 & 13.75 & 44.375 & 41.875 & 389.3 & 78 \\
NE-9 & 10 & 50 & 40 & 256.3 & 75 \\
NE-10 & 12.5 & 57.5 & 30 & 232.7 & 63 \\
NE-11 & 12.5 & 40 & 47.5 & 347.5 & 89 \\
NE-12 & 15 & 47.5 & 37.5 & 401.3 & 69 \\
NE-13 & 12.5 & 48.75 & 38.75 & 328.9 & 73 \\
NE-14 & 10 & 60 & 30 & 197.5 & 65 \\
\hline
\end{tabular}

This equation and the two-dimensional contour plot demonstrated that a high proportion of surfactant $\left(X_{2}\right)$ and a low proportion of both oil $\left(X_{1}\right)$ and cosurfactant $\left(X_{3}\right)$ minimized the globule size of the formulation. The grey area in the system adjacent to the corner of the surfactant in the triangle signifies the minimum globule size of the formulations. The globule size was affected by the concentration of oil. The average globule size was found to be increased significantly in the formulations containing the highest level of oil (NE-3, NE-4, and NE-12). The globule size increased with increasing oil concentration, which has been suggested to be the main reason for the inadequate amount of surfactant/cosurfactant required to cover oil droplets and coalesce the globules [14,38]. Consistently, formulations with the lowest level of oil (NE-1, NE-2, NE-9, and NE-14) showed a smaller globule size, which can be attributed to the use of an appropriate concentration of surfactant/cosurfactant mixture. This provided a sufficient reduction in the free energy of the system, which afforded a strong mechanical barrier protecting the formed globules from coalescence. Systems with a mean globule size below $200 \mathrm{~nm}$ achieve the criteria for SNEDS [39].

\subsubsection{Effect of NE Components on the Stability Index}

The results varied from $59 \%$ in NE-3 to $91 \%$ in NE-2, which were fitted to the special cubic model with a $p$-value of 0.0001 . The contour plot shows the effect of the NE components on the stability index of the formulations as depicted in Figure 2c. The regression equation of the fitted special cubic model for the stability index $\left(\mathrm{Y}_{2}\right)$ was generated using Equation (3).

Stability index $\left(\mathrm{Y}_{2}\right)=-41.223 \mathrm{X}_{1}+63.548 \mathrm{X}_{2}+89.798 \mathrm{X}_{3}+120.573 \mathrm{X}_{1} \mathrm{X}_{2}+143.673 \mathrm{X}_{1} \mathrm{X}_{3}$ $-6.346 X_{2} X_{3}-37.568 X_{1} X_{2} X_{3}$.

Equation (3) and the triangular two-dimensional contour plot demonstrated that the high proportion of cosurfactant $\left(X_{3}\right)$ and the low proportions of both oil $\left(X_{1}\right)$ and surfactant $\left(X_{2}\right)$ maximized the stability index of the formulations. The dark blue area in the system adjacent to the corner of the 
cosurfactant in the triangle represents the maximum stability index of the formulations. The results show that the stability index of formulations is affected by the concentration of cosurfactant. The formulation (NE-2) containing the highest level of cosurfactant showed the highest stability index. In contrast, formulations (NE-1, NE-3, NE-10, and NE-14) that contained low levels of cosurfactant showed the lowest stability index. The thermodynamic stability of NEs arises from their extremely low interfacial tension. In general, surfactants alone cannot decrease the interfacial free energy sufficiently, so the addition of cosurfactant is necessary to produce thermodynamically stable NE systems [40]. The same finding has been reported for microemulsion-based anthocyanin systems that showed that the stability of the system was improved by increasing the concentration of cosurfactant [41].

\subsubsection{Multiple Response Optimization Using the Desirability Function}

The triangular dimensional contour plot displays the effect of the levels of the components on the desirability function after the optimization of $\mathrm{NE}$ as demonstrated in Figure $2 \mathrm{~d}$. It is obvious from the figure that the high proportions of cosurfactant $\left(X_{3}\right)$ and the low proportions of both oil $\left(X_{1}\right)$ and surfactant $\left(\mathrm{X}_{2}\right)$ maximize the desirability of the formulation. The violet area in the system adjacent to the corner of the cosurfactant in the triangle represents the maximum desirability of the formulation. The composition of NE-2 as depicted in Table 2 resulted in minimum globule size and maximum stability index, and was therefore used in the preparation of FBX-SNELTs.

\subsection{Morphological Examination Using TEM}

Globule size is a critical factor in SNEDS performance because it influences the rate and extent of drug release, as well as drug absorption [39]. TEM images with different magnifications (Figure 3) revealed that the formed colloidal dispersion is characterized by uniform globule size distribution, a nano-size range of approximately $200 \mathrm{~nm}$, and no globule aggregation. This globule size agreed with the results measured by Zetasizer as given in Table 2.
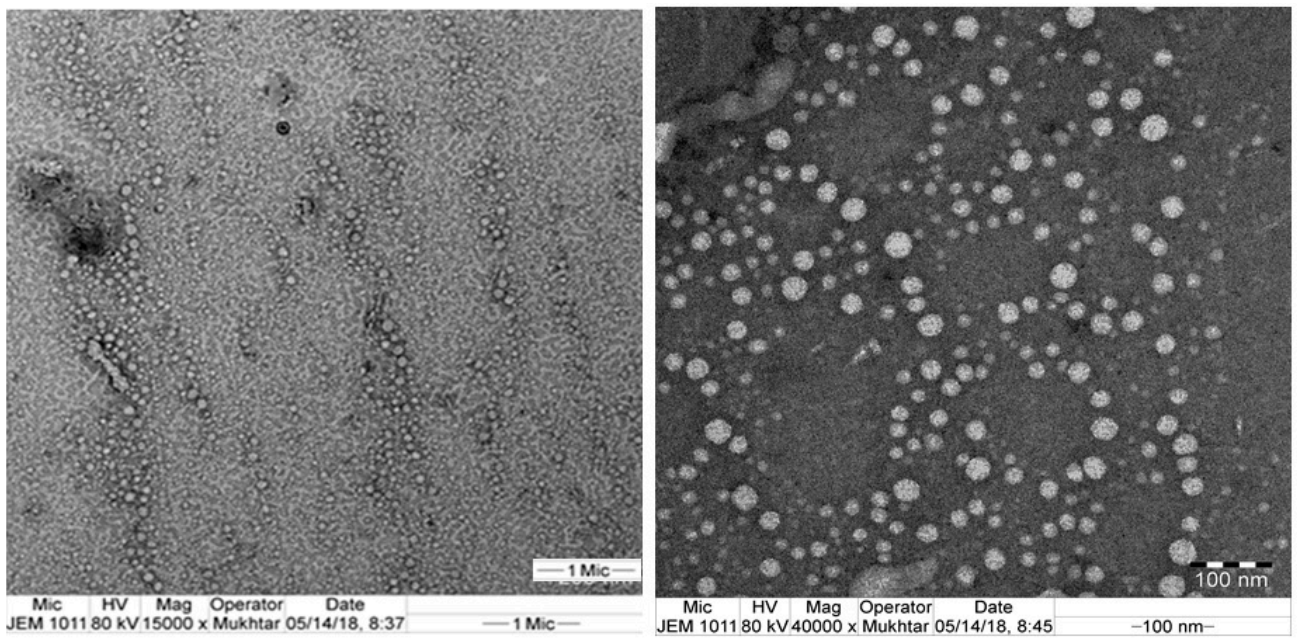

Figure 3. Photomicrographs of the optimized FBX-SNEDS by TEM image.

\subsection{Formulation of FBX-SNELTS}

FBX-SNELTs were successfully prepared with lactose as the most suitable diluent to give the minimum disintegration time and the best dissolution profile when compared with Avicel PH-101 or starch-containing formulations. Fifteen formulations were successfully prepared according to BBD (Table 3) and investigated for their in vitro disintegration (Figure 4a) and in vitro dissolution (Figure $4 b-d$ ). Mannitol was added to provide adequate hardness to the SNELTs and improve the stability of the final product as reported in a previous study of lyophilized cyclophosphamide [42]. Gelatin, as a water-soluble polymer, served as a matrix-forming binder to maintain mechanical strength 
during manufacturing and patient handling [43]. Fumed silica, which is an insoluble excipient with a large surface area, was used to increase the amount of adsorbed drug on its surface and facilitate its distribution in the buccal cavity upon disintegration, and consequently enhance its absorption via the mucosal membrane [44]. Xylitol was used to enhance the hardness of the SNELTs and to impart a desirable sweet taste as reported in a previous study on taste masking of the oral administration of ranitidine disintegrating tablets [45]. Croscarmellose sodium, lactose, and xylitol were subsequently added as superdisintegrant, diluent, and sweetening agents, respectively. All the components were homogeneously mixed until the formation of a slurry that was poured into empty pockets of tablet blister packs that were finally lyophilized. Furthermore, HPMC and gelatin solution were successfully used in previous work in the preparation of SNELTs $[23,46]$.

Table 3. Independent factor percentages in the formulations of FBX-SNELTs in a randomized order as suggested by a Box-Behnken design.

\begin{tabular}{cccc}
\hline Formula Code & $\mathbf{X}_{\mathbf{1}}$ & $\mathbf{X}_{\mathbf{2}}$ & $\boldsymbol{X}_{\mathbf{3}}$ \\
\hline SNELT-1 & 6.0 & 1.0 & 0.75 \\
SNELT-2 & 6.0 & 2.0 & 0.5 \\
SNELT-3 & 8.0 & 1.0 & 0.5 \\
SNELT-4 & 8.0 & 2.0 & 0.75 \\
SNELT-5 & 4.0 & 1.0 & 0.5 \\
SNELT-6 & 6.0 & 2.0 & 0.5 \\
SNELT-7 & 6.0 & 1.0 & 0.25 \\
SNELT-8 & 8.0 & 3.0 & 0.5 \\
SNELT-9 & 4.0 & 2.0 & 0.75 \\
SNELT-10 & 4.0 & 2.0 & 0.25 \\
SNELT-11 & 6.0 & 3.0 & 0.25 \\
SNELT-12 & 8.0 & 2.0 & 0.25 \\
SNELT-13 & 6.0 & 3.0 & 0.75 \\
SNELT-14 & 6.0 & 2.0 & 0.5 \\
SNELT-15 & 4.0 & 3.0 & 0.5 \\
\hline
\end{tabular}

Abbreviations: $X_{1}$, groscarmellose sodium percentage; $X_{2}$, gelatin solution concentration; $X_{3}$, hydroxypropyl methylcellulose percentage.

a)

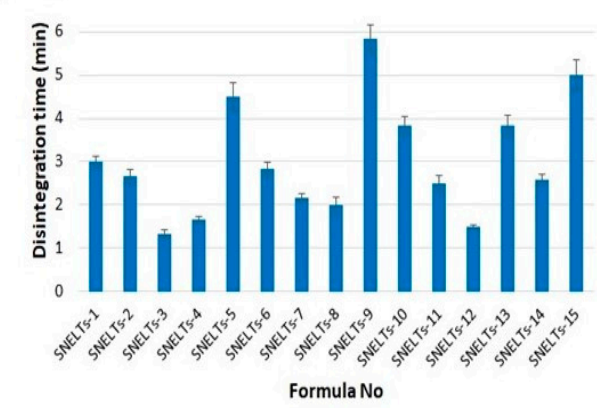

c)

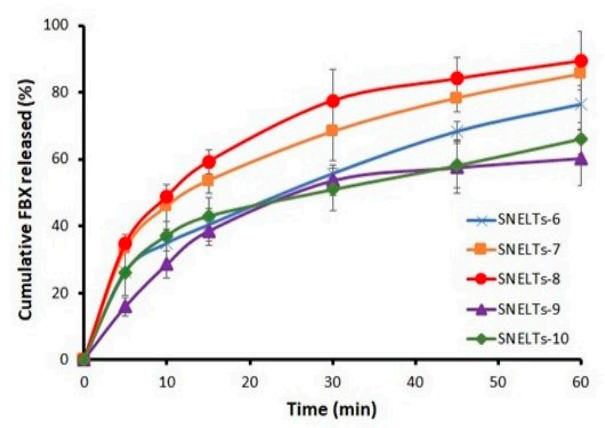

b)

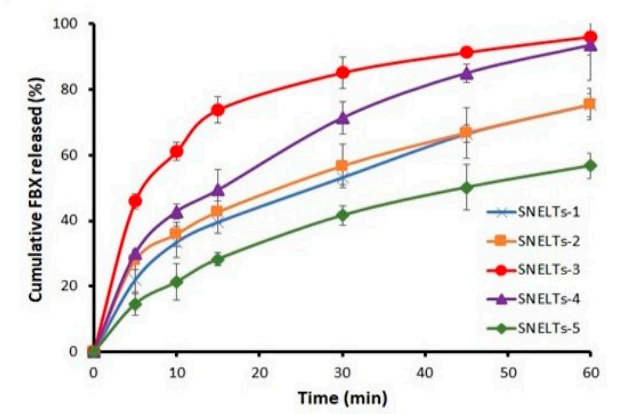

d)

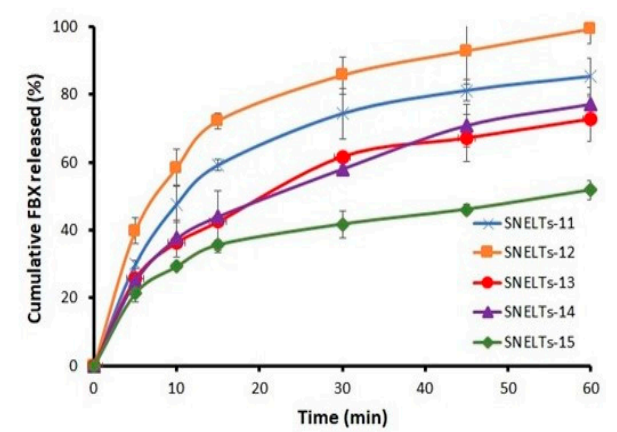

Figure 4. Disintegration (a) and dissolution profiles (b-d) of the prepared SNELTs. 


\subsection{Evaluation of the Prepared FBX-SNELTs}

The prepared FBX-SNELTs were evaluated for various parameters. The weight uniformity of SNELTs for all the formulations met the pharmacopeia requirement, and the results ranged between $127.2 \pm 1.19$ and $135.3 \pm 0.7 \mathrm{mg}$, suggesting the proper formulation of the SNELTs. The thickness of the SNELTs ranged from $5.014 \pm 0.19$ to $5.170 \pm 0.45 \mathrm{~mm}$. The FBX content was found to be more than $93 \%$ for all formulations, within the pharmacopeia limits of $90.0 \%$ to $110.0 \%$. The friability test for all formulations was less than $1 \%$, which complies with the pharmacopeia specification, and indicates good mechanical strength. These results indicate the ability of the SNELTs to resist mechanical stress conditions during handling.

\subsection{In Vitro Disintegration Study}

The in vitro disintegration time for the formulations ranged from $1.33 \mathrm{~min}$ (SNELTs-3) to $5.83 \mathrm{~min}$ (SNELTs-9) as demonstrated in Figure 4a. There is a direct relationship between the disintegration time and the percentage of hydroxypropyl methylcellulose $\left(X_{3}\right)$, and the concentration of gelatin solution $\left(X_{2}\right)$ (Figure 5a). On the other hand, the disintegration time was inversely proportional to the percentage of croscarmellose sodium $\left(X_{1}\right)$ (Figure 5a). Formulations containing the highest level of either $X_{2}$ or $X_{3}$ and the lowest level of $X_{1}$ showed the longest disintegration time, as shown in formulations SNELTs-9 and SNELTs-15 (Figure 4a). In contrast, formulations containing the lowest level of either $X_{2}$ or $X_{3}$ and the highest level of $X_{1}$ showed the shortest disintegration time, as in formulations SNELTs-3 and SNELTs-12 (Figure 4a), which is in agreement with reported results [47]. For instance, Marais et al. reported that the increase in croscarmellose sodium concentration reduced the disintegration time of furosemide tablets. This finding may be due to its ability to enhance the rate and extent of liquid uptake and penetration into the tablets, hastening their breakdown and disintegration [47]. AlHusban et al. noticed that the disintegration time of clonidine tablets was decreased by decreasing the concentration of gelatin in the solution [48]. Also, Dave et al. reported a similar finding for chlorpheniramine maleate lyophilized tablets. The formulation containing a high concentration of gelatin showed a longer disintegration time, which the investigators attributed to slow uptake of water from the medium and an increase in the swelling disintegration time [22]. Also, the presence of HPMC $\left(\mathrm{X}_{1}\right)$ as a matrix-forming polymer with high concentration increased the disintegration time of the tablet, which could be attributed to the formation of a high level of cross-linking polymer network that decreases the tablet porosity and increases its hardness [49].

\subsection{In Vitro Dissolution Study}

The release profiles for the fifteen formulations are presented in Figure $4 \mathrm{~b}-\mathrm{d}$. The cumulative percent of FBX from all formulations ranged from 51.8\% (SNELTs-15) to 99.2\% (SNELTs-12). The results illustrate that there is a relationship between disintegration time and the dissolution profile. The formulations with the shortest disintegration time, SNELTs-3, SNELTs-4, and SNELTs-12, showed the highest cumulative released amount of FBX. In contrast, the formulations with the longest disintegration time, SNELTs-5, SNELTs-9, and SNELTs-15, showed the lowest cumulative released amount of FBX. This result, which is attributed to the short disintegration time of SNELTs, led to the rapid breakdown of the tablet into small particles that increased the surface area exposed to the medium and consequently enhanced the dissolution of the drug [50]. 

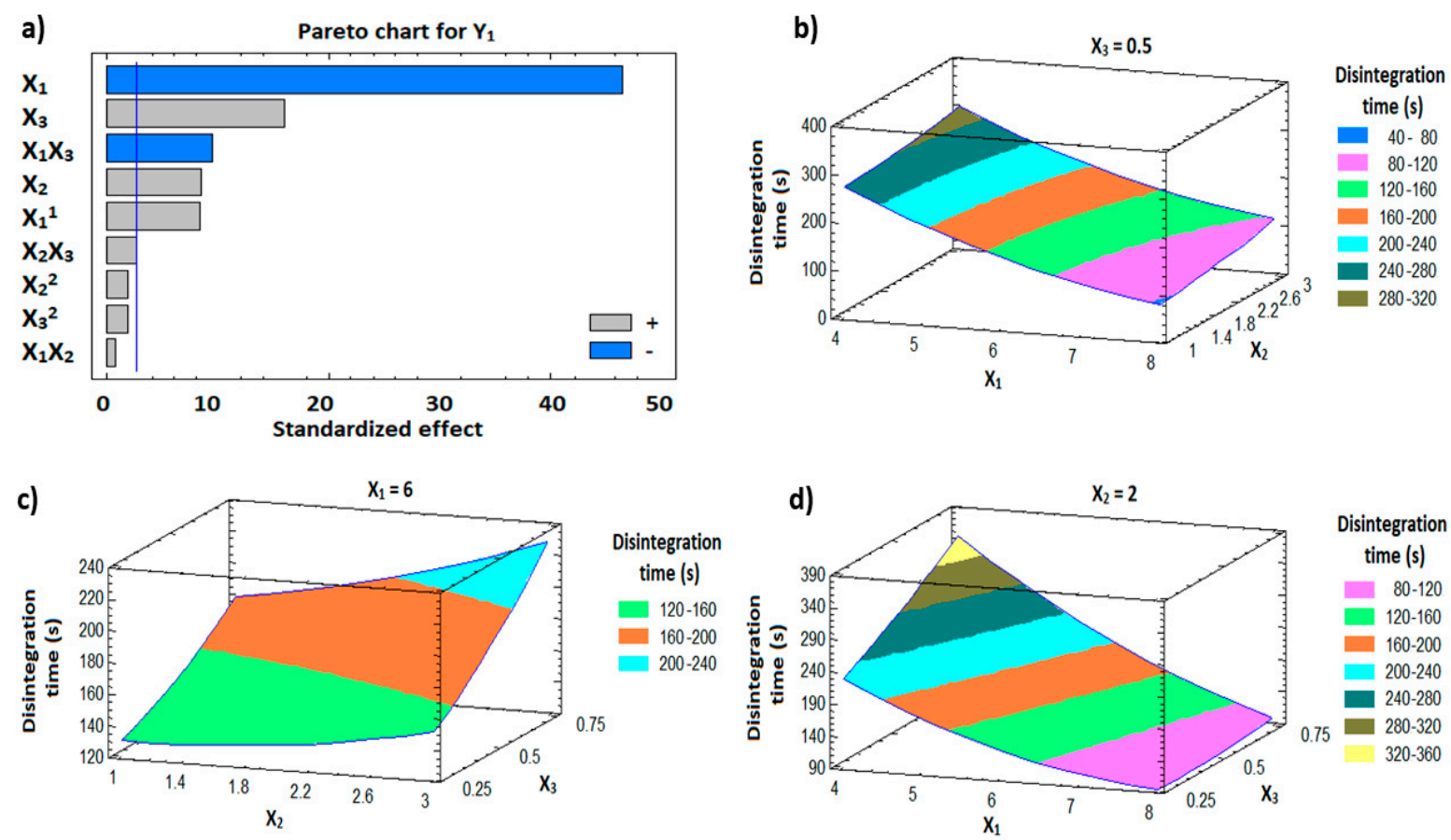

Figure 5. Pareto chart (a) and response surface plots (b-d) showing the effect of the independent variables on the disintegration time $\left(\mathrm{Y}_{1}\right)$.

\subsection{Response Surface Methodology for Optimization of FBX-SNELTs}

BBD was utilized for the optimization of FBX-SNELTs to minimize disintegration time and maximize FBX dissolution within $1 \mathrm{~h}$. The experimental design matrix with different levels of the factors is compiled in Table 3.

\subsubsection{Influence of the Independent Variables on Tablet Disintegration $\left(\mathrm{Y}_{1}\right)$}

For the fast disintegration of tablets, it is essential to ensure that tablets break down rapidly into smaller fragments to yield the largest possible surface area available to the dissolution media [51]. The prepared FBX-SNELTs showed marked variation in disintegration times ranging from 1.33 min for formulation (SNELTs-3) to $5.83 \mathrm{~min}$ for formulation (SNELTs-9). The effect of the investigated factors on the disintegration timeis demonstrated in the 3D response surface plots (Figure $5 b-d)$. A polynomial Equation (4) was generated as follows:

$$
\begin{aligned}
& \text { In vitro disintegration time }\left(Y_{1}, \mathrm{~min}\right)=498.75-98.75 \mathrm{X}_{1}-26.667 \mathrm{X}_{2}+313.333 \mathrm{X}_{3}+6.354 \mathrm{X}_{1}^{2} \\
& +1.25 \mathrm{X}_{1} \mathrm{X}_{2}-55.0 \mathrm{X}_{1} \mathrm{X}_{3}+5.417 \mathrm{X}_{2}{ }^{2}+30.0 \mathrm{X}_{2} \mathrm{X}_{3}+86.667 \mathrm{X}_{3}{ }^{2}
\end{aligned}
$$

The ANOVA results (Table 4) and Pareto chart (Figure 5a) depict a significant negative effect of $\mathrm{X}_{1}$ and the interaction term $\left(\mathrm{X}_{1} \mathrm{X}_{3}\right)$ on the disintegration time of FBX-SNELTs $\left(\mathrm{Y}_{1}\right)$, with $p$-values of 0.0001 and 0.0002 , respectively. This result shows the presence of an inverse relationship between these factors and the disintegration of tablets. As the concentration of croscarmellose increased, the tablet disintegrated faster. However, ANOVA also showed a significant positive effect of $X_{2}, X_{3}$, and the quadratic term of $X_{1}$ and the interaction term $\left(X_{2} X_{3}\right)$ corresponding to the disintegration time of FBX-SNELTs with $p$-values of $0.0004,0.0001,0.0004$ and 0.0484 , respectively. As a result, formulations containing the lowest level of either $X_{2}$ or $X_{3}$ and the highest level of $X_{1}$ showed the shortest disintegration times. This result could be due to the high porosity of tablets and the adequate amount of superdisintegrant required to swell and break down the tablets as previously reported by Elkordy et al. [51]. Croscarmellose sodium is a hydrophilic polymer and absorbs many times its weight 
in water to rapidly swell the tablets. This wicking action will spontaneously replace the tablet-air interface with a tablet-water interface and maintain a capillary flow leading to rapid disintegration [52].

Table 4. Statistical analysis of variance (ANOVA) of the responses $\left(\mathrm{Y}_{1}\right.$ and $\left.\mathrm{Y}_{2}\right)$ results.

\begin{tabular}{|c|c|c|c|c|c|c|}
\hline \multirow{2}{*}{ Factors } & \multicolumn{3}{|c|}{ Disintegration Time $\left(\mathrm{Y}_{1}\right)$, min } & \multicolumn{3}{|c|}{ Cumulative Release after $60 \min \left(Y_{2}\right), \%$} \\
\hline & Estimate & F-Ratio & $p$-Value & Estimate & F-Ratio & $p$-Value \\
\hline $\mathrm{X}_{1}$ & -190.0 & 2166.00 & $0.0001 *$ & 35.83 & 311.63 & $0.0001 *$ \\
\hline$x_{2}$ & 35.0 & 73.50 & 0.0004 * & -3.58 & 3.10 & 0.1384 \\
\hline$x_{3}$ & 65.0 & 253.50 & $0.0001 *$ & -8.5 & 17.54 & 0.0086 * \\
\hline $\mathrm{X}_{1} \mathrm{X}_{1}$ & 50.83 & 71.56 & 0.0004 * & -2.83 & 0.90 & 0.3864 \\
\hline$x_{1} x_{2}$ & 5.0 & 0.75 & 0.4261 & -0.9 & 0.10 & 0.7665 \\
\hline$x_{1} x_{3}$ & -55.0 & 90.75 & $0.0002 *$ & 0.05 & 0.00 & 0.9868 \\
\hline$x_{2} x_{2}$ & 10.83 & 3.25 & 0.1313 & -2.83 & 0.90 & 0.3864 \\
\hline$x_{2} x_{3}$ & 15.0 & 6.75 & 0.0484 * & -1.35 & 0.22 & 0.6579 \\
\hline$x_{3} x_{3}$ & 10.83 & 3.25 & 0.1313 & 9.72 & 10.58 & 0.0226 * \\
\hline $\mathrm{R}^{2}$ & & 99.81 & & & 98.58 & \\
\hline Adj. $R^{2}$ & & 99.48 & & & 96.01 & \\
\hline SEE & & 5.77 & & & 2.87 & \\
\hline MAE & & 2.44 & & & 1.23 & \\
\hline
\end{tabular}

Note: * Significant effect of factors on individual responses. Abbreviations: $X_{1}$, croscarmellose sodium percentage; $\mathrm{X}_{2}$, gelatin solution concentration; $\mathrm{X}_{3}$, Hydroxypropyl methylcellulose percentage; $\mathrm{X}_{1} \mathrm{X}_{2}, \mathrm{X}_{1} \mathrm{X}_{3}, \mathrm{X}_{2} \mathrm{X}_{3}$, the interaction term between the factors; $X_{1} X_{1}, X_{2} X_{2}$, and $X_{3} X_{3}$, the quadratic terms between the factors; $R^{2}$, R-squared; Adj- $R^{2}$, adjusted R-squared; SEE, standard error of estimate; MAE, mean absolute error.

On the other hand, the formulations containing a high level of either $\mathrm{X}_{2}$ or $\mathrm{X}_{3}$ and a low level of $X_{1}$ showed the longest disintegration time. Gelatin and HPMC were used as structure-forming excipients in these formulations. The disintegration of the tablet is affected by pore structure and bonding structure within the tablet as the pores facilitate rapid water penetration into the tablet to rupture the bonds and break down the tablets into small fragments. The binder effect of gelatin and HPMC in these formulations decreases the porosity of tablets, and thus the medium penetration into the tablets decreases, which slows down the disintegration process [53]. Liew and Peh reported that HPMC prolonged the disintegration time of tablets due to the formation of a high level of cross-linking polymer network that decreases the porosity of the tablets [49]. Also, increasing the concentration of gelatin increases bond strength between the tablet particles leading to an increase in tablet hardness and disintegration time as previously reported by Widjaja et al. [54].

\subsubsection{Influence of Independent Variables on Cumulative FBX Release $\left(\mathrm{Y}_{2}\right)$}

The dissolution profiles of FBX-SNELTs formulation are represented in Figure $4 \mathrm{~b}-\mathrm{d}$. The cumulative FBX release from the SNELTs showed marked variation, ranging from 51.8\% (SNELTs-15) to 99.2\% (SNELTs-12). A polynomial Equation (5) was generated as follows:

$$
\begin{aligned}
& \text { Cumulative FBX release }\left(Y_{2}, \%\right)=30.438+13.631 X_{1}+6.579 X_{2}-89.633 X_{3}-0.354 X_{1}^{2} \\
& -0.225 X_{1} X_{2}+0.05 X_{1} X_{3}-1.417 X_{2}^{2}-2.7 X_{2} X_{3}+77.733 X_{3}^{2}
\end{aligned}
$$

Statistical analysis (Table 4) showed a significant positive effect of $\mathrm{X}_{1}$ and $\mathrm{X}_{3}{ }^{2}$ on the dissolution of FBX from SNELTs, with $p$-values of 0.0001 and 0.0226 , respectively. This revealed a direct relationship between $X_{1}$ and $Y_{2}$, i.e., percentage increase of croscarmellose directly correlates with a cumulative increase in FBX release. On the other hand, $X_{3}$ showed a significant negative effect on the cumulative FBX release from SNELTs as demonstrated in the Pareto charts in Figure 6a. The effects of the studied factors on cumulative FBX release are graphically illustrated in the 3D response surface plots shown in Figure $6 b-d$. It is evident that the dissolution profile of FBX-SNELTs formulations containing the lowest level of $X_{3}$ and the highest level of $X_{1}$ showed the highest cumulative release of FBX from 
SNELTs. On the other hand, the lowest cumulative release of FBX was observed in the formulation containing the highest level of $X_{3}$ and the lowest level of $X_{1}$. Drug dissolution is highly dependent on the tablet disintegration; as a result, the higher the concentration of superdisintegrant used, the higher the cumulative drug released, as previously reported by Tanuwijaya et al. [55]. This result could be attributed to the high amount of superdisintegrant that causes the rapid disintegration and breakdown of SNELTs into small particles, increasing the surface area that is exposed to the medium and enhancing its dissolution, and vice versa [56].
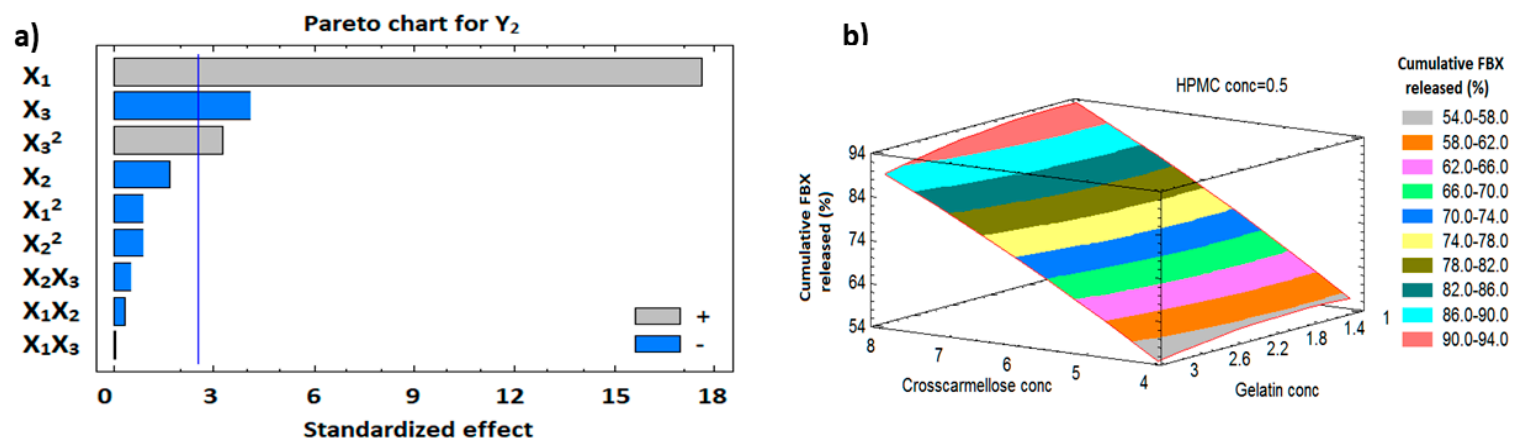

c)

d)
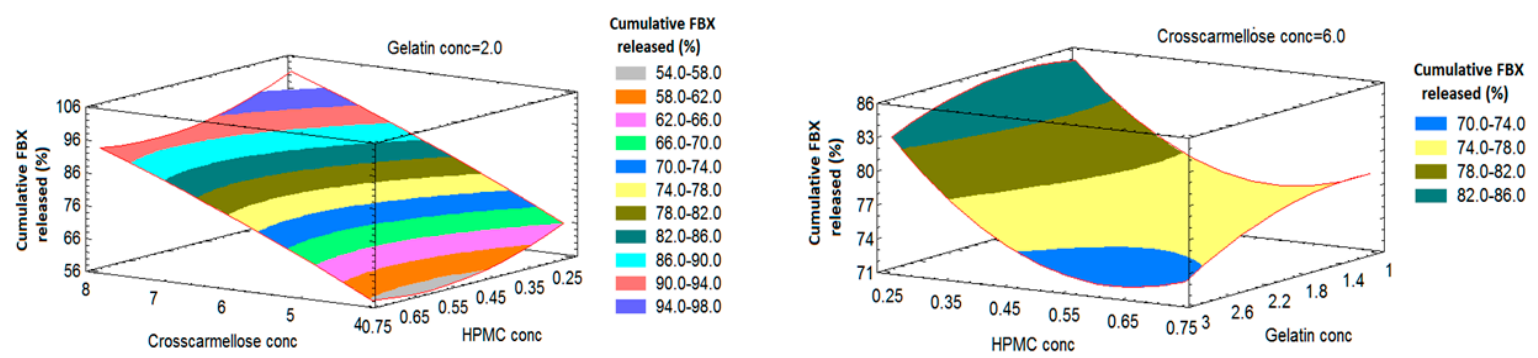

Figure 6. Pareto chart (a) and response surface plots $(\mathbf{b}-\mathbf{d})$ showing the effect of the independent variables on cumulative FBX release $\left(\mathrm{Y}_{2}\right)$.

\subsubsection{Optimization}

Numerical optimization following the desirability function approach was applied to predict the optimum FBX-SNELT composition with minimum disintegration time and maximum FBX dissolution within $1 \mathrm{~h}$. This optimized FBX-SNELT contains $20 \mathrm{mg}$ FBX dissolved in $100 \mathrm{mg}$ SNEDS, $10 \mathrm{mg}$ of both fumed silica and lactose, and $5 \mathrm{mg}$ of both mannitol and Xylitol. These ingredients were dispersed in gelatin solution and mixed with the optimum concentrations of both HPMC and croscarmellose sodium. The optimum level of the independent factor was found to be $5.73 \%$ of croscarmellose, $1.93 \%$ of gelatin solution, and $0.43 \%$ of HPMC. The optimized formulation achieved the desirability requirements with a function of 0.829 . The prepared optimized FBX-SNELTs complied with the pharmacopeia requirement and specifications for weight uniformity, thickness, content uniformity, and friability. Also, the optimized FBX-SNELTs exhibited a disintegration time of 2.74 min with a $75.5 \%$ cumulative release of FBX. The observed parameters are in good agreement with the predictions, with a percentage error of less than $5 \%$. 
The cumulative release of FBX from the optimized FBX-SNELTs was compared to the marketed FBX tablets. Figure 7a shows that the release of FBX from SNELTs was significantly higher and faster than from the marketed FBX tablet, the former showing a release of $\sim 75 \%$ in $1 \mathrm{~h}$ compared to $\sim 40 \%$ by the marketed FBX, also in $1 \mathrm{~h}$. Interestingly, FBX-SNELTs released the same amount of FBX in $10 \mathrm{~min}$ compared to the release by the marketed FBX tablet in $1 \mathrm{~h}$. This enhancement of FBX dissolution appears to improve its absorption and hence its oral bioavailability as reported [23,57].

a)

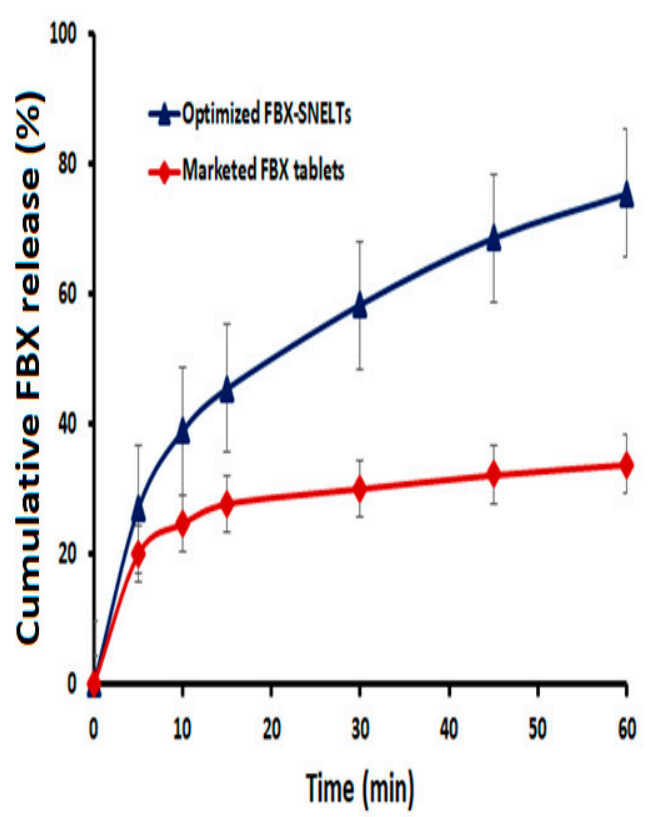

b)

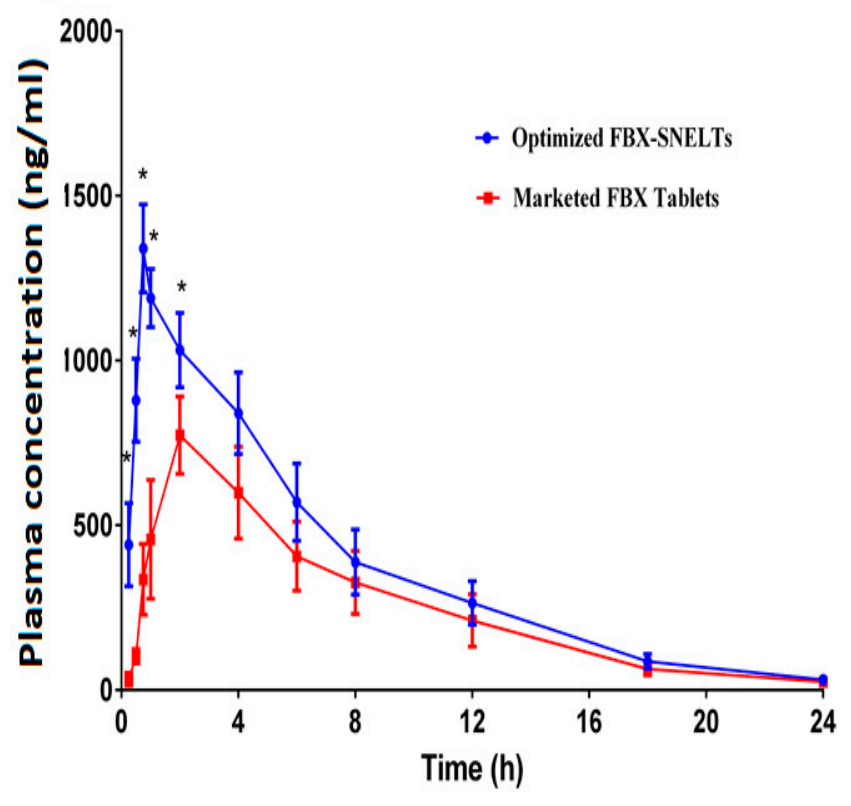

Figure 7. Comparative release profiles (a) and plasma concentration-time curves (b) between the optimized FBX-SNELTs and marketed tablets.

\subsection{In Vivo Pharmacokinetic Study in Healthy Human Volunteers}

The plasma concentration-time profiles of FBX after the oral administration of a single dose of the optimized FBX-SNELTs and the marketed FBX tablets are compared in Figure 7b. The pharmacokinetic parameters of the clinical study are represented in Table 5. The results indicate that the maximum plasma concentration $\left(C_{\max }\right)$ of FBX-SNELTs was $1340.0 \pm 134.0 \mathrm{ng} / \mathrm{mL}$ within $45 \mathrm{~min}\left(\mathrm{~T}_{\max }\right)$, compared to the marketed FBX tablets for which it was $773.5 \pm 117.6 \mathrm{ng} / \mathrm{mL}$ within $120 \mathrm{~min}\left(\mathrm{~T}_{\max }\right)$. These findings meant that SNELTs improved the rate and extent of FBX absorption. Also, FBX-SNELTs showed a higher area under the curve $(8885.9 \pm 1578.3 \mathrm{ng} / \mathrm{mL} \cdot \mathrm{h})$ in comparison to the marketed tablets $(6069.9 \pm 1640 \mathrm{ng} / \mathrm{mL} \cdot \mathrm{h})$. The relative bioavailability of FBX in the SNELT formulation was $146.4 \%$ compared to the marketed tablets. The obtained results suggest that the incorporation of FBX in SNEDS with minimum globule size, loading onto a carrier with large surface area, and lyophilizing in fluffy porous tablets lead to an increase in the rate and extent of absorption as well as improving the oral bioavailability of the drug [23]. The improved absorption of FBX was probably due to the enhanced solubilization of FBX that could be directly absorbed without the dissolution step, which is considered the rate-limiting step for drug absorption in Biopharmaceutical Classification System (BCS) Class II compounds [57]. 
Table 5. Pharmacokinetic parameters of the optimized FBX-SNELTs compared to the marketed FBX tablets (mean $\pm \mathrm{SD} ; n=6)$.

\begin{tabular}{ccc}
\hline PK Parameters & Optimized FBX-SNELTs & Marketed FBX Tablets \\
\hline $\mathrm{C}_{\max }(\mathrm{ng} / \mathrm{mL})$ & $1340.0 \pm 134.0$ & $773.5 \pm 117.6$ \\
$\mathrm{~T}_{\max }(\mathrm{min})$ & $45.0 \pm 0.0$ & $120.0 \pm 0.0$ \\
$\mathrm{t}_{1 / 2}(\mathrm{~h})$ & $4.0 \pm 0.27$ & $4.28 \pm 0.50$ \\
$\mathrm{AUC}_{0-\mathrm{t}}(\mathrm{ng} / \mathrm{mL} \mathrm{h})$ & $8885.9 \pm 1578.3$ & $6069.9 \pm 1640.0$ \\
$\mathrm{AUC}_{0-\text { inf }}(\mathrm{ng} / \mathrm{mL} \mathrm{h})$ & $9068.6 \pm 1590.0$ & $6230.7 \pm 1715.7$ \\
$\mathrm{AUMC}_{0-\text { inf }}\left(\mathrm{ng} / \mathrm{mL} \mathrm{h}^{2}\right)$ & $60,175.0 \pm 12,212.0$ & $46,481.8 \pm 15,071.3$ \\
$\mathrm{~K}_{\mathrm{el}}\left(\mathrm{h}^{-1}\right)$ & $0.173 \pm 0.01$ & $0.165 \pm 0.02$ \\
$\mathrm{MRT}^{2}(\mathrm{~h})$ & $6.61 \pm 0.19$ & $7.39 \pm 0.39$ \\
Relative BA $(\%)$ & 146.4 & -
\end{tabular}

Abbreviations: $\mathrm{C}_{\max }$, the maximum plasma concentration; $\mathrm{T}_{\max }$, Time to maximum plasma concentration; $\mathrm{t}_{1 / 2}$, the elimination half-life; $\mathrm{AUC}_{0-\mathrm{t}}$, the area under the plasma concentration-time curve from zero time to the last

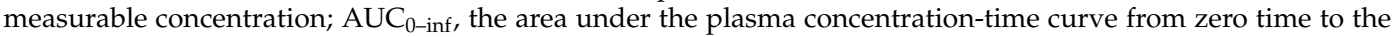
infinity; AUMC, the area under the first moment curve; Kel, the terminal elimination rate constant; MRT, the mean residence time; $\mathrm{BA}$, the bioavailability.

\section{Conclusions}

The study establishes FBX-SNELTs to improve the poor bioavailability of FBX, and importantly to enhance its clinical usage. The optimized FBX-NE is composed of $10 \%$ castor oil, $40 \%$ PEG 40 stearate, and 50\% Transcutol and led to a SNEDS with $175.7 \mathrm{~nm}$ globule size and 91\% stability index. A Box-Behnken design was utilized to optimize the level of the lyophilized tablet excipients to develop FBX-SNELTs with minimum disintegration time and maximum drug release. The optimized FBX-SNELTs are composed of 5.73\% croscarmellose sodium, 1.93\% gelatin solution concentration, and $0.43 \%$ hydroxypropyl methylcellulose. This formulation exhibited a disintegration time of $2.74 \mathrm{~min}$ and released $75.5 \%$ of the FBX within $1 \mathrm{~h}$. Comparing the relative bioavailability and the pharmacokinetics parameters of optimized FBX-SNELTs with marketed FBX tablets in healthy human volunteers showed a significant improvement in FBX bioavailability in the developed SNELTs (146.4\%). The results from these in vitro and in vivo studies support the usage of FBX-SNELTs in the treatment and management of gout patients due to their superiority in enhancing FBX bioavailability.

Author Contributions: Conceptualization, Y.A.A.-A., K.M.H. and K.M.E.-S.; Data curation, Y.A.A.-A., K.M.H., K.M.E.-S., W.S.A. and M.K.S.; Formal analysis, K.M.H., W.S.A. and K.M.E.-S.; Funding acquisition, K.M.E.-S.; Investigation, Y.A.A.-A. and K.M.H.; Methodology, Y.A.A.-A., K.M.H. and K.M.E.-S.; Project administration, K.M.E.-S.; Resources, K.M.E.-S.; Software, K.M.E.-S.; Supervision, K.M.H. and K.M.E.-S.; Validation, K.M.H. and K.M.E.-S.; Writing—original draft, Y.A.A.-A., K.M.H. and K.M.E.-S.; Writing-review \& editing, Y.A.A.-A., K.M.H., K.M.E.-S., W.S.A. and M.K.S.; All authors have read and agreed to the published version of the manuscript.

Funding: This project was funded by the Deanship of Scientific Research (DSR) at King Abdulaziz University, Jeddah, under grant number [RG-15-166-40].

Acknowledgments: The authors, therefore, acknowledge DSR with thanks for technical and financial support.

Conflicts of Interest: The authors declare no conflict of interest.

\section{References}

1. Perez-Ruiz, F.; Dalbeth, N.; Bardin, T. A Review of Uric Acid, Crystal Deposition Disease, and Gout. Adv. Ther. 2014, 32, 31-41. [CrossRef] [PubMed]

2. Altan, A.; Shiozawa, A.; Bancroft, T.; Singh, J.A. A real-world study of switching from allopurinol to febuxostat in a health plan database. J. Clin. Rheumatol. 2015, 21, 411-418. [CrossRef] [PubMed]

3. Li, S.; Yang, H.; Guo, Y.; Wei, F.; Yang, X.; Li, D.; Li, M.; Xu, W.; Li, W.; Sun, L.; et al. Comparative efficacy and safety of urate-lowering therapy for the treatment of hyperuricemia: A systematic review and network meta-analysis. Sci. Rep. 2016, 6, 1-12. [CrossRef] [PubMed] 
4. Khanna, D.; Fitzgerald, J.D.; Khanna, P.P.; Bae, S.; Singh, M.K.; Neogi, T.; Pillinger, M.H.; Merill, J.; Lee, S.; Prakash, S.; et al. American college of rheumatology guidelines for management of gout. part 1: Systematic nonpharmacologic and pharmacologic therapeutic approaches to hyperuricemia. Arthritis Care Res. 2012, 64, 1431-1446. [CrossRef] [PubMed]

5. Bisht, M.; Bist, S. Febuxostat: A novel agent for management of Hyperuricemia in gout. Indian J. Pharm. Sci. 2012, 73, 597. [CrossRef] [PubMed]

6. Becker, M.A.; Schumacher, H.R.; Wortmann, R.L.; MacDonald, P.A.; Eustace, D.; Palo, W.A.; Streit, J.; Joseph-Ridge, N. Febuxostat Compared with Allopurinol in Patients with Hyperuricemia and Gout. N. Engl. J. Med. 2005, 353, 2450-2461. [CrossRef] [PubMed]

7. Dudhe, P.B.; Chavare, P.D.; Shelke, P.S. Spectrophotometric Determination of Febuxostat from Bulk and Tablet Dosage form by Area under Curve Method. Int. J. ChemTech Res. 2017, 10, 183-189.

8. Kumar, K.K.; Srinivas, L.; Kishore, V.S.; Basha, S.N. Formulation and Evaluation of Poorly Soluble Febuxostat Orodispersable Tablet. AjaddCoUk 2014, 2, 191-202.

9. Satalkar, P.; Elger, B.S.; Hunziker, P.; Shaw, D. Challenges of clinical translation in nanomedicine: A qualitative study. Nanomed. Nanotechnol. Biol. Med. 2016, 12, 893-900. [CrossRef]

10. El-Say, K.M.; El-Sawy, H.S. Polymeric nanoparticles: Promising platform for drug delivery. Int. J. Pharm. 2017, 528, 675-691. [CrossRef] [PubMed]

11. Rao, S.V.R.; Yajurvedi, K.; Shao, J. Self-nanoemulsifying drug delivery system (SNEDDS) for oral delivery of protein drugs: III. In vivo oral absorption study. Int. J. Pharm. 2008, 362, 16-19. [CrossRef] [PubMed]

12. Abdelghani, G.M.; Nouh, A.T. Self-nanoemulsifying drug-delivery systems for potentiated anti-inflammatory activity of diacerein. Int. J. Nanomed. 2018, 13, 6585-6602.

13. Al-Subaie, M.M.; Hosny, K.M.; El-Say, K.M.; Ahmed, T.A.; Aljaeid, B.M. Utilization of nanotechnology to enhance percutaneous absorption of acyclovir in the treatment of herpes simplex viral infections. Int. J. Nanomed. 2015, 10, 3973-3985. [CrossRef]

14. Ahmed, O.A.A.; Badr-Eldin, S.M.; Tawfik, M.K.; Ahmed, T.A.; El-Say, K.M.; Badr, J.M. Design and Optimization of Self-Nanoemulsifying Delivery System to Enhance Quercetin Hepatoprotective Activity in Paracetamol-Induced Hepatotoxicity. J. Pharm. Sci. 2014, 103, 602-612. [CrossRef] [PubMed]

15. Balakumar, K.; Raghavan, C.V.; Selvan, N.T.; Prasad, R.H.; Abdu, S. Self nanoemulsifying drug delivery system (SNEDDS) of Rosuvastatin calcium: Design, formulation, bioavailability and pharmacokinetic evaluation. Colloids Surf. B Biointerfaces 2013, 112, 337-343. [CrossRef] [PubMed]

16. Villar, A.M.S.; Naveros, B.C.; Campmany, A.C.C.; Trenchs, M.A.; Rocabert, C.B.; Bellowa, L.H. Design and optimization of self-nanoemulsifying drug delivery systems (SNEDDS) for enhanced dissolution of gemfibrozil. Int. J. Pharm. 2012, 431, 161-175. [CrossRef] [PubMed]

17. Sharma, A.; Sharma, U.S. Liposomes in drug delivery: Progress and limitations. Int. J. Pharm. 1997, 154, 123-140. [CrossRef]

18. MuÈller, R.H.; MaĖder, K.; Gohla, S. Solid lipid nanoparticles (SLN) for controlled drug delivery-A review of the state of the art. Eur. J. Pharm. Biopharm. 2000, 50, 161-177. [CrossRef]

19. Pouton, C.W. Lipid formulations for oral administration of drugs: Non-emulsifying, self-emulsifying and 'self-microemulsifying' drug delivery systems. Eur. J. Pharm. Sci. 2000, 11, S93-S98. [CrossRef]

20. Tan, A.; Rao, S.; Prestidge, C.A. Transforming lipid-based oral drug delivery systems into solid dosage forms: An overview of solid carriers, physicochemical properties, and biopharmaceutical performance. Pharm. Res. 2013, 30, 2993-3017. [CrossRef]

21. Mahmoud, E.A.; Bendas, E.R.; Mohamed, M.I. Preparation and evaluation of self-nanoemulsifying tablets of carvedilol. AAPS Pharmscitech 2009, 10, 183-192. [CrossRef] [PubMed]

22. Ahmed, T.A.; El-Say, K.M.; Hosny, K.M.; Aljaeid, B.M. Development of optimized self-nanoemulsifying lyophilized tablets (SNELTs) to improve finasteride clinical pharmacokinetic behavior. Drug Dev. Ind. Pharm. 2018, 44, 652-661. [CrossRef] [PubMed]

23. El-Say, K.M.; Ahmed, T.A.; Ahmed, O.A.A.; Hosny, K.M.; Abd-Allah, F.I. Self-Nanoemulsifying Lyophilized Tablets for Flash Oral Transmucosal Delivery of Vitamin K: Development and Clinical Evaluation. J. Pharm. Sci. 2017, 106, 2447-2456. [CrossRef] [PubMed] 
24. Seo, Y.G.; Kim, D.W.; Yousaf, A.M.; Park, J.H.; Chang, P.S.; Baek, H.H.; Lim, S.J.; Kim, J.O.; Yong, C.S.; Choi, H.G. Solid self-nanoemulsifying drug delivery system (SNEDDS) for enhanced oral bioavailability of poorly water-soluble tacrolimus: Physicochemical characterisation and pharmacokinetics. J. Microencapsul. 2015, 32, 503-510. [CrossRef] [PubMed]

25. Inugala, S.; Eedara, B.B.; Sunkavalli, S.; Dhurke, R.; Kandadi, P.; Jukanti, R.; Bandari, S. Solid self-nanoemulsifying drug delivery system (S-SNEDDS) of darunavir for improved dissolution and oral bioavailability: In vitro and in vivo evaluation. Eur. J. Pharm. Sci. 2015, 74, 1-10. [CrossRef] [PubMed]

26. Kang, J.H.; Oh, D.H.; Oh, Y.K.; Yong, C.S.; Choi, H.G. Effects of solid carriers on the crystalline properties, dissolution and bioavailability of flurbiprofen in solid self-nanoemulsifying drug delivery system (solid SNEDDS). Eur. J. Pharm. Biopharm. 2012, 80, 289-297. [CrossRef] [PubMed]

27. Nasr, A.; Gardouh, A.; Ghorab, M. Novel solid self-nanoemulsifying drug delivery system (S-SNEDDS) for oral delivery of olmesartan medoxomil: Design, formulation, pharmacokinetic and bioavailability evaluation. Pharmaceutics 2016, 8, 20. [CrossRef] [PubMed]

28. Mohd, A.B.; Sanka, K.; Bandi, S.; Diwan, P.V.; Shastri, N. Solid self-nanoemulsifying drug delivery system (S-SNEDDS) for oral delivery of glimepiride: Development and antidiabetic activity in albino rabbits. Drug Deliv. 2015, 22, 499-508. [CrossRef] [PubMed]

29. Sastry, S.V.; Nyshadham, J.R.; Fix, J.A. Recent technological advances in oral drug delivery-A review. Pharm. Sci. Technolo. Today 2000, 3, 138-145. [CrossRef]

30. El-Nesr, O.H.; Yahiya, S.A.; El-Gazayerly, O.N. Effect of formulation design and freeze-drying on properties of fluconazole multilamellar liposomes. Saudi Pharm. J. 2010, 18, 217-224. [CrossRef]

31. Gutiérrez, J.M.; González, C.; Maestro, A.; Solè, I.; Pey, C.M.; Nolla, J. Nano-emulsions: New applications and optimization of their preparation. Curr. Opin. Colloid Interface Sci. 2008, 13, 245-251. [CrossRef]

32. Lawrence, M.J.J.; Rees, G.D. Microemulsion-based media as novel drug delivery systems. Adv. Drug Deliv. Rev. 2000, 45, 89-121. [CrossRef]

33. Khosravan, R.; Grabowski, B.A.; Wu, J.T.; Joseph-Ridge, N.; Vernillet, L. Pharmacokinetics, pharmacodynamics and safety of febuxostat, a non-purine selective inhibitor of xanthine oxidase, in a dose escalation study in healthy subjects. Clin. Pharmacokinet. 2006, 45, 821-841. [CrossRef]

34. Boby, J.G. A Review on Self Emulsifying Nanoemulsion. Open Access J. Pharm. Res. 2017, 1, 1-17. [CrossRef]

35. Mensah, M.B.; Awudza, J.A.M.; Brien, P.O. Castor oil: A suitable green source of capping agent for nanoparticle syntheses and facile surface functionalization. Royal Soc. Open Sci. 2018, 5, 180824. [CrossRef] [PubMed]

36. Schmidts, T.; Dobler, D.; Nissing, C.; Runkel, F. Influence of hydrophilic surfactants on the properties of multiple W/O/W emulsions. J. Colloid Interface Sci. 2009, 338, 184-192. [CrossRef] [PubMed]

37. Chime, S.A.; Kenechukwu, F.C.; Attama, A.A. Nanoemulsions-Advances in Formulation, Characterization and Applications in Drug Delivery. In Nanotechnology and Nanomaterials "Application of Nanotechnology in Drug Delivery"; Sezer, A.D., Ed.; InTech: Rijeka, Croatia, 2014; Chapter 3, pp. 77-126.

38. Dapčević Hadnadev, T.; Dokić, P.; Krstonošić, V.; Hadnadev, M. Influence of oil phase concentration on droplet size distribution and stability of oil-in-water emulsions. Eur. J. Lipid Sci. Technol. 2013, 115, 313-321. [CrossRef]

39. Aboul-einien, M. Design and in-Vitro Evaluation of Olanzapine- Loaded Self Nanoemulsifying Drug Delivery System. Int. J. Ind. Pharm. Life Sci. 2012, 2, 12-32.

40. Resende, K.X.; Corrêa, M.A.; Oliveira, A.G.D.; Scarpa, M.V. Effect of cosurfactant on the supramolecular structure and physicochemical properties of non-ionic biocompatible microemulsions. Revista Brasileira de Ciências Farmacêuticas 2008, 44, 35-42. [CrossRef]

41. Chen, J.; Ma, X.H.; Yao, G.L.; Zhang, W.T.; Zhao, Y. Microemulsion-based anthocyanin systems: Effect of surfactants, cosurfactants, and its stability. Int. J. Food Prop. 2018, 21, 1152-1165. [CrossRef]

42. Teagarden, D.L.; Baker, D.S.; Baheti, A.; Kumar, L.; Bansal, A.K. Excipients used in lyophilization of small molecules. J. Excip. Food Chem. 2010, 1, 41-54.

43. Darkwah, J. Characterisation of Freeze Dried Amino Acids and Gelatin Based Rapidly Disintegrating Tablets, De Montfort University, 2011. Available online: https:/www.dora.dmu.ac.uk/handle/2086/6018 (accessed on 9 June 2019).

44. Zhang, X.; Cresswell, M. Silica-Based Amorphous Drug Delivery Systems. In Inorganic Controlled Release Technology; Elsevier: Amsterdam, The Netherlands, 2016; pp. 93-137. ISBN 9780080999913. 
45. Hesari, Z.; Shafiee, A.; Hooshfar, S.; Mobarra, N.; Mortazavic, S.A. Formulation and taste masking of ranitidine orally disintegrating tablet. Iran. J. Pharm. Res. 2016, 15, 677-686. [PubMed]

46. Marais, A.F.; Song, M.; de Villiers, M.M. Effect of compression force, humidity and disintegrant concentration on the disintegration and dissolution of directly compressed furosemide tablets using croscarmellose sodium as disintegrant. Trop. J. Pharm. Res. 2003, 2, 125-135.

47. AlHusban, F.; Perrie, Y.; Mohammed, A. Preparation, Optimisation and Characterisation of Lyophilised Rapid Disintegrating Tablets Based on Gelatin and Saccharide. Curr. Drug Deliv. 2010, 7, 65-75. [CrossRef]

48. Dave, V.; Yadav, R.B.; Ahuja, R.; Yadav, S. Formulation design and optimization of novel fast dissolving tablet of chlorpheniramine maleate by using lyophilization techniques. Bull. Fac. Pharmacy Cairo Univ. 2017, 55, 31-39. [CrossRef]

49. Liew, K.B.; Peh, K.K. Investigation on the effect of polymer and starch on the tablet properties of lyophilized orally disintegrating tablet. Arch. Pharm. Res. 2015. [CrossRef] [PubMed]

50. Ahmed, I.; Aboul-Einien, M. In vitro and in vivo evaluation of a fast-disintegrating lyophilized dry emulsion tablet containing griseofulvin. Eur. J. Pharm. Sci. 2007, 32, 58-68. [CrossRef]

51. Elkordy, A.A.; Tan, X.N.; Essa, E.A. Spironolactone release from liquisolid formulations prepared with Capryol $^{\mathrm{TM}}$ 90, Solutol@HS-15 and Kollicoat@SR 30 D as non-volatile liquid vehicles. Eur. J. Pharm. Biopharm. 2013, 83, 203-223. [CrossRef] [PubMed]

52. Desai, P.M.; Er, P.X.H.; Liew, C.V.; Heng, P.W.S. Functionality of Disintegrants and Their Mixtures in Enabling Fast Disintegration of Tablets by a Quality by Design Approach. AAPS PharmSciTech 2014, 15, 1093-1104. [CrossRef]

53. Audu-peter, J.D.; Ibrahim, M.A. Interactions of binder, disintegrant and compression pressure in tablets ii: Effect of the differences in their levels on friability, hardness and disintegration time. J. Pharm. Allied Sci. 2016, 11, 2133-2141.

54. Widjaja, B.; Setyawan, D.; Moechtar, J. Development of piroxicam orally disintegrating tablets by freeze drying method. Int. J. Pharm. Pharm. Sci. 2013, 5, 795-798.

55. Tanuwijaya, J. Karsono the effects of crospovidone and croscarmellose sodium as superdisintegrants on the characteristics of piroxicam nanoparticles ODT (orally disintegrating tablet). Int. J. PharmTech Res. 2013, 5, 1590-1597.

56. Nazmi, M.; Ashraful Islam, S.M.; Bhuiyan, M.A.; Reza, M.S. Effect of superdisintegrants and their mode of incorporation on disintegration time and release profile of carbamazepine from immediate release tablet. J. Appl. Pharm. Sci. 2013, 3, 80-84. [CrossRef]

57. Arzani, G.; Haeri, A.; Daeihamed, M.; Bakhtiari-Kaboutaraki, H.; Dadashzadeh, S. Niosomal carriers enhance oral bioavailability of carvedilol: Effects of bile salt-enriched vesicles and carrier surface charge. Int. J. Nanomed. 2015, 10, 4797-4813. [CrossRef]

(C) 2020 by the authors. Licensee MDPI, Basel, Switzerland. This article is an open access article distributed under the terms and conditions of the Creative Commons Attribution (CC BY) license (http://creativecommons.org/licenses/by/4.0/). 